\title{
Selection, management, and early outcome of 113 patients with symptomatic gall stones treated by percutaneous cholecystolithotomy
}

\author{
S Cheslyn-Curtis, A R Gillams, R C G Russell, J J Donald, S P Lake, C A Ainley, \\ A R W Hatfield, W R Lees
}

\begin{abstract}
Between January 1988 and December 1990, 283 patients with symptomatic gall stones were referred for non-operative treatment. After ultrasound scanning including a functional assessment, $220(78 \%)$ patients were found to be suitable for percutaneous cholecystolithotomy. Of these, 113 underwent the procedure including 10 in whom extracorporeal shockwave lithotripsy or methyl tert-butyl ether therapy had failed. Forty four patients underwent extracorporeal shockwave lithotripsy, methyl tertbutyl ether therapy or rotary lithotripsy, 46 chose laparoscopic cholecystectomy or minicholecystectomy and 27 declined treatment. Percutaneous cholecystolithotomy was successfully performed in 100 patients. Thirty four patients were a high operative risk and 14 presented with an acute complication of gall stone disease. Complications developed in $\mathbf{1 5}$ patients, all of whom were managed conservatively and most occurred during development of the technique. Outcome has been assessed clinically and by ultrasound scanning in 92 patients with a median follow up period of 14 months (six to 37 months). Seventy nine per cent were completely cured of their symptoms. Ninety three per cent of gall bladders were shown to be functioning and nine (9.8\%) contained stones, although five of these are believed to have developed from residual fragments. Percutaneous cholecystolithotomy is a safe, non-operative treatment for symptomatic gall stones and enabled the patient to fully recover within two to three weeks; it has a definite role in the management of the elderly and high risk patient but its use for the treatment of other groups is likely to remain controversial.
\end{abstract}

(Gut 1992; 33: 1253-1259)

In recent years, there has been a move away from open surgical techniques in biliary disease with an increasing use of therapeutic endoscopy for the extraction of bile duct stones and the stenting of biliary strictures. Similarly in the past decade, as recently reviewed, ${ }^{1}$ several non-invasive and minimally invasive techniques have been pioneered for the management of gall bladder stones.

The ability to puncture the gall bladder percutaneously under radiological control has resulted in the development of new diagnostic and therapeutic techniques. The transhepatic puncture of the gall bladder has been used for cholecystography and cholangiography, for aspiration of bile or pus for culture in suspected cases of acute cholecystitis or empyema, and for biopsy of lesions within the gall bladder. ${ }^{2}$ Direct percutaneous access to the gall bladder has opened new avenues for the non-operative management of gall stone disease and is being increasingly used, particularly in elderly and high risk patients for the treatment of acute cholecystitis, empyema and the perforated gall bladder with localised abscess formation. ${ }^{3}$ Other therapeutic options made possible by percutaneous puncture of the gall bladder include contact dissolution of gall stones with solvents ${ }^{4}$ and percutaneous cholecystolithotomy.

The percutaneous extraction of gall stones was first described in 1985, for the treatment of high risk patients with acute cholecystitis, and was carried out in up to five stages using a transhepatic tract. ${ }^{56}$ The technique evolved from the introduction of percutaneous cholecystostomy as an alternative to surgical cholecystostomy and utilised well established techniques for dilating percutaneous tracts and stone extraction. In 1988, Kellett et al adapted the technique of percutaneous nephrolithotomy for the extraction of gall bladder stones. ${ }^{7}$ The gall bladder is accessed transperitoneally and not transhepatically, as large cannulae, which make stone extraction easier, cause unnecessary trauma to the liver.

Percutaneous cholecystolithotomy avoids the disadvantages of conventional cholecystectomy which are pain related to a large, unsightly wound, a week of hospitalisation and four to six weeks' convalescence. Less invasive methods of minicholecystectomy and laparoscopic cholecystectomy are replacing the conventional operation and offer similar advantages to percutaneous cholecystolithotomy without the risk of stone recurrence. Not all patients, however, such as the elderly and high risk, are suitable for these new operative techniques. There may also be a place for preserving a useful gall bladder in young patients with solitary or few stones, who may not reform stones. ${ }^{8}$ In this prospective study, we describe our unique experience in the selection and management of 113 patients treated by percutaneous cholecystolithotomy and assess early outcome with regard to symptoms, stone recurrence and gall bladder function.

\section{Methods}

PATIENTS

Referral pattern

Between January 1988 and December 1990, data 
were collected prospectively on 283 patients with symptomatic gall stones referred for nonoperative treatment. Fifty four per cent of patients were referred by general practitioners, $43 \%$ were tertiary referrals from other consultant surgeons and physicians in England, Wales, and the Channel Islands, and 3\% were admitted through the Accident and Emergency Department. The reasons for referral were either at the patient's request because of an unwillingness to undergo an operation $(70 \%)$ or because the patient was a high operative risk (30\%).

\section{Selection}

Patients were assessed in a special gall stone clinic to determine their suitability for the various treatment techniques available in our unit. These techniques included percutaneous cholecystolithotomy, extracorporeal shockwave lithotripsy, contact dissolution therapy with methyl tert-butyl ether, minicholecystectomy, and latterly, laparoscopic cholecystectomy and percutaneous rotary lithotripsy. Selection for these techniques depended on the clinical features including patient fitness, a detailed ultrasound assessment and patient preference. Each patient was given an ASA grading' as part of the anaesthetic department audit. Ultrasound scanning was used to determine the stone size and number; gall bladder position, accessibility, wall thickness and function; and appearance of the bile duct. Gall bladder function (emptying) was assessed by measuring the change in the fasting gall bladder volume after a fatty meal. Long axis and transverse images of the gall bladder were obtained and the volume calculated, using the ellipsoid method, ${ }^{10}$ from the following formula:

Gall bladder volume $(\mathrm{ml})=\frac{\pi}{6}$.length. width. height.

A reduction in volume of $30 \%$ or more was regarded as satisfactory gall bladder emptying. Computed tomography of the gall bladder was initially done on all patients but latterly, only patients who were being considered for extracorporeal shockwave lithotripsy (patients with one to three gall stones which were less than $3 \mathrm{~cm}$ in diameter) were scanned to determine stone density (calcification). Patients with stones of any composition, size and number contained in a thin walled gall bladder with a fasting volume greater than $15 \mathrm{ml}$ were found to be suitable for percutaneous cholecystolithotomy. Neither an acute complication of gall stone disease nor a non-functioning gall bladder, if caused by a stone impacted in Hartmann's pouch, was regarded as a contraindication to treatment. Patients with thick walled, contracted gall bladders were excluded, not only because the gall bladder was diseased but also because of the technical difficulty in puncturing and dilating a track through a thick, fibrosed, gall bladder wall.

\section{Technique}

The procedure was adapted from the technique of percutaneous nephrolithotomy." It was carried out under general anaesthesia or local anaesthesia with intravenous sedation. A percu- taneous cholecystogram was done and then the fundus of the gall bladder was punctured with a Kellett needle (152 mm long dwell sheathed needle, Becton Dickinson, Ontario, Canada), using a combination of ultrasound and fluoroscopic guidance. A guide wire was placed in the gall bladder for the entire procedure as a safety measure. The track was dilated to $28-30 \mathrm{~F}$ using Teflon (USCI) and telescoping metal dilators (Keymed, Southend-on-Sea, UK) before inserting an Amplatz Teflon sheath (Lewis Medical, London, UK). The gall bladder was inspected with a rigid cholecystoscope (Olympus, Keymed, Southend-on-Sea, UK) and stones up to $10 \mathrm{~mm}$ in diameter were flushed out or removed with forceps. Stones too large to pass through the Amplatz sheath were fragmented by intracorporeal electrohydraulic, or ultrasound lithotripsy and removed piecemeal. The gall bladder was carefully inspected and a spot film taken to ensure that all the stones had been removed. At the end of the procedure, a Foley catheter was introduced through the Amplatz sheath and placed on free drainage. A 'tubogram' was carried out, as an outpatient 10 days later and the catheter removed, provided that the biliary tree was clear of stones and that there was no extravasation of contrast into the peritoneal cavity.

In patients with a stone impacted in Hartmann's pouch or with an acute complication caused by gall stones, the gall bladder was electively decompressed by percutaneous cholecystostomy, carried out under local anaesthesia, for seven to 10 days before the stones were removed. The purpose of this was to allow the stone to disimpact or for the acute complication to resolve. When the total procedure was done under local anaesthesia, staged dilatation of the track over five to seven days was undertaken.

\section{Adjuvant therapy}

Adjuvant therapy was not given to the first 44 successfully treated patients. It was introduced after the observation that some tiny fragments, adherent to or embedded in the gall bladder mucosa, were difficult to remove completely and that some gall bladders showed cholesterolosis. Therefore, in the subsequent 56 patients adjuvant therapy with chenodeoxycholic acid $7 \mathrm{mg} / \mathrm{kg} /$ day and ursodeoxycholic acid $5 \mathrm{mg} / \mathrm{kg} /$ day was given for an arbitrary period of three months after the procedure.

\section{Outcome}

Patients were assessed clinically and by ultrasound scanning at approximately three months, six monthly to two years and then yearly after percutaneous cholecystolithotomy. Symptoms were compared with those before treatment and were scored as follows: (0) no symptoms; (1) major symptoms cured, patient pleased with result of treatment; (2) some improvement, patient not wholly satisfied with result of treatment; (3) no change in symptoms. An ultrasound scan was done, as already described to assess stone status and gall bladder emptying. 


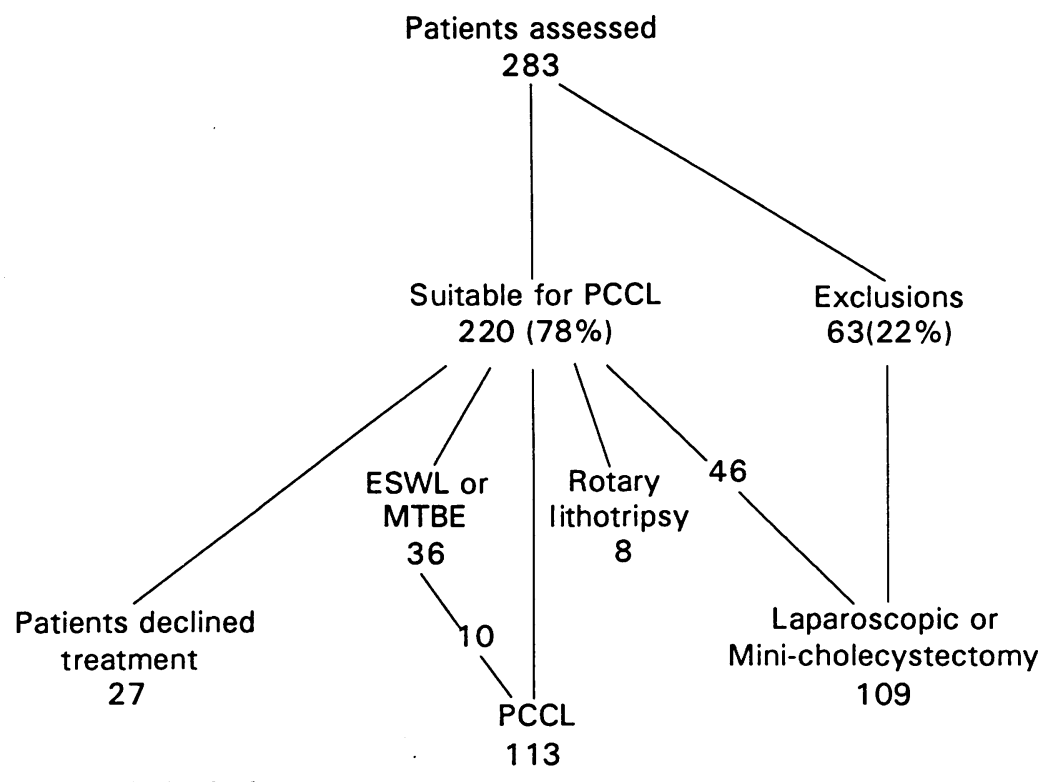

Patient selection for the various treatment options. $P C C L=$ percutaneous cholecystolithotomy, $E S W L=$ extracorporeal shockwave lithotripsy, $M T B E=$ methyl tert-butyl ether. grade III (severe systemic disease which limited activity) and 10 patients as ASA grade IV (incapacitating systemic disease which was a constant threat to life). These 34 patients were referred $(68 \%$ by consultants from other hospitals) for non-operative treatment because they were high risk for surgery.

\section{PROCEDURE}

Percutaneous cholecystolithotomy was carried out under general anaesthesia except in the 10 patients with an ASA grade of IV. The procedure was successful in 100 of 113 patients (89\%) and completed in a single stage in 72 . Failures were because of failed puncture and dilatation (five), to loss of access (one), and to residual cystic duct stones (seven). Bile peritonitis developed in the patient in whom access was lost and a surgical cholecystostomy was done, followed by a further percutaneous removal of residual stones. Of the seven patients with residual cystic duct stones, five had patent cystic ducts and two had nonfunctioning gall bladders before treatment. The first two of these patients were advised to undergo cholecystectomy which was done two and 10 weeks later and the remainder have been followed to determine outcome. stones were suitable for percuta cholecystolithotomy and have undergone tr ment as shown in the Figure.

\section{PATIENTS TREATED BY PERCUTANEOUS CHOLECYSTOLITHOTOMY}

The 113 patients who underwent percutaneous cholecystolithotomy had a median age of 56 years (range 18-89) with a male to female ratio of $1: 2 \cdot 4$. Five were referred after failure of oral dissolution therapy and 10 were selected after unsuccessful extracorporeal shockwave lithotripsy or methyl tert-butyl ether dissolution therapy.

\section{CLINICAL PRESENTATION}

All patients were symptomatic and had proven gall stones. The majority of patients (89) gave a history of biliary colic and included 12 who had received treatment in the past for an acute complication (Table I). The 14 patients who presented with an acute complication of gall stone disease had a median age of 70 years (range 31-78) and seven were regarded as high risk for surgery.

FITNESS FOR SURGERY

Twenty four patients were classified as ASA

TABLE I Clinical presentation

\begin{tabular}{lll}
\hline & $\begin{array}{l}\text { Presentation } \\
(n=113)\end{array}$ & $\begin{array}{l}\text { Past } \\
\text { history } \\
(n=I 2)\end{array}$ \\
\hline Diagnosis & 89 & \\
Biliary colic & 10 & \\
$\begin{array}{l}\text { Non-specific/atypical biliary symptoms } \\
\text { Acute complication }\end{array}$ & 6 & 6 \\
$\begin{array}{l}\text { Acute cholecystitis } \\
\text { Perforated empyema/liver abscess }\end{array}$ & 2 & \\
$\begin{array}{l}\text { Mucocoele } \\
\text { Cholangitis }\end{array}$ & 2 & 1 \\
Jaundice (with empyema in 1) & 2 & 3 \\
Pancreatitis (with jaundice in 1) & 1 & 2 \\
\hline
\end{tabular}

\section{STAGED PROCEDURES}

Twenty eight procedures were done in two to four stages. The procedure was staged in 14 of 16 patients with a stone impacted in Hartmann's pouch (six of whom presented with an acute gall bladder). The stone disimpacted in eight of these patients after seven to 10 days decompression and was removed successfully at the second stage, whereas five of six patients with persistent stone impaction required more than one session for stone clearance. Cystic duct patency was regained in 15 of 16 patients with Hartmann's pouch stones (Table II). Decompression of 13 of the 14 acute gall bladders for seven to 10 days resulted in resolution of acute cholecystitis (six), mucocoeles (two), perforated empyemas associated with liver abscesses (two), and jaundice alone, with empyema or with pancreatitis (three) before stone extraction was undertaken. The procedure failed in one patient because of failed puncture and dilatation and in another, whose

TABLE II Outcome of gall bladder function in patients with non-functioning gall bladders before percutaneou cholecystolithotomy (PCCL) caused by a Hartmann pouch stone or an acute complication

\begin{tabular}{lcc}
\hline & $\begin{array}{l}\text { Hartmann } \\
\text { pouch stone } \\
(n=16)\end{array}$ & $\begin{array}{l}\text { Acute gall } \\
\text { bladder } \\
(n=14)\end{array}$ \\
\hline Pre PCCL & & \\
$\quad$ Functioning & 0 & 0 \\
$\quad$ Non-functioning & 16 & 14 \\
PCCL & 15 & 12 \\
$\quad$ Success/patent cystic duct & 0 & 1 \\
$\quad$ Failure - puncture/dilatation & $1^{\star}$ & $1^{\star}$ \\
Outcome cystic duct stone & $2^{\star}$ & $2^{\star}$ \\
Lost to follow up & 11 & 8 \\
Functioning & $2^{\star}$ & $2^{\star}$ \\
\hline Non-functioning & & \\
\hline
\end{tabular}

Function was assessed by determining gall bladder emptying pre and post fatty meal or a patent cystic duct at cholangiography. stone. ${ }^{\star}$ Same patients. Six patients with an acute gall bladder had a Hartmann pouch 
cystic duct became obstructed during extraction of a Hartmann pouch stone (Table II). Two of three jaundiced patients underwent endoscopic sphincterotomy to remove duct stones after successful percutaneous cholecystolithotomy and the stone passed spontaneously in the third. Eleven patients with incomplete stone clearance at the first procedure underwent a second (nine) or third (two) cholecystolithotomy after redilatation of the percutaneous tract. This was done electively in 10 of the 11 patients because of a prolonged procedure time caused by excessive stone burden or difficult stone extraction.

\section{DURATION OF PROCEDURE}

The median total procedure time was 69 minutes (range 25-210). The first 10 procedures were performed in a median 166 minutes but with increasing experience and modification of the technique, there was a gradual reduction in procedure time to 51 minutes for the last 50 patients. The duration of the procedure depended on difficulties encountered during puncturing and dilatating, the stone load and the experience of the operators. Multiple hard stones, greater than $1 \mathrm{~cm}$ in diameter, each requiring lithotripsy and removal piecemeal, took much longer to remove than a solitary stone of less than $1 \mathrm{~cm}$ in diameter.

GALL BLADDER STONES AND MUCOSA

The number and mean size of the stones removed from each gall bladder are shown in Table III. In 52 patients, the stones were $10 \mathrm{~mm}$ or less in diameter and were removed whole without fragmentation. Intracorporeal lithotripsy was used in 30 of the 48 patients with larger stones. The appearance of the gall bladder mucosa was documented for the last 53 patients and is noted in Table III.

\section{POSTOPERATIVE COURSE}

\section{Complications}

Complications occurred in 15 patients as listed in Table IV. Transient cholangitis only occurred

TABLE III Stone characteristics and appearance of gall bladder mucosa

\begin{tabular}{cr}
\hline & $\begin{array}{c}\text { Patients } \\
(n)\end{array}$ \\
\hline Stone number Median 5, range 1-800 & $\mathrm{n}=100$ \\
Solitary & 24 \\
$2-5$ & 29 \\
$6-10$ & 12 \\
$11-20$ & 16 \\
$21-50$ & 11 \\
$51-100$ & 4 \\
$>100$ & $\mathrm{4}$ \\
Stone size (mm) Median 10, range 3-30 & 100 \\
5 or less & 19 \\
$6-10$ & 33 \\
$11-15$ & 20 \\
$16-20$ & 11 \\
$21-25$ & 15 \\
26-30 & 2 \\
Mucosal appearance & $\mathrm{n}=53$ \\
Normal & 23 \\
Frondy/oedematous & 15 \\
Submucosal cholesterol (cholesterolosis) & 10 \\
Submucosal pigment & 2 \\
Not recorded & 3 \\
\hline
\end{tabular}

TABLE IV Complications after percutaneous cholecystolithotomy

\begin{tabular}{ll}
\hline Morbidity & $(n=15)$ \\
\hline Subhepatic bile collection & 4 \\
Cholangitis & 3 \\
Perforated gall bladder & 2 \\
Delayed tract formation & 1 \\
Bowel puncture & 0 \\
Wound infection & 2 \\
Chest infection & 2 \\
Deep venous thrombosis & 1 \\
Mortality & 0 \\
\hline
\end{tabular}

when antibiotic prophylaxis was omitted. Subhepatic bile collections were managed by percutaneous drainage in one patient and conservatively in the other three. The two gall bladder perforations were caused by an inexperienced radiologist learning the technique and were managed conservatively by percutaneously draining the gall bladder for seven to 10 days to allow the perforation to heal and performing stone extraction at a second stage. Most complications occurred with the first few procedures when the technique was being developed.

\section{Hospital stay}

The overall median hospital stay from the first stage of percutaneous cholecystolithotomy was three days (range one to 33). It was shorter for single stage procedures (median two days, range one to 14) than those done in multiple stages (median five days, range four to 25). The median hospital stay from the first stage in patients with acute complications was 12 days (range three to 33). The longest hospital stay was in a patient with an empyema associated with liver abscesses which required drainage until the abscess cavities resolved.

\section{Recovery}

The median time to full recovery as judged by the patient was 12 days - that is, two days after the Foley drainage catheter was removed and ranged from two to 28 days. The median time for return to employment was 18 days.

Details of the procedure of percutaneous cholecystolithotomy are summarised in Table V.

Outcome

Of 100 patients who underwent successful percutaneous cholecystolithotomy, two have died

TABLE V Summary of percutaneous cholecystolithotomy (PCCL)

\begin{tabular}{|c|c|c|}
\hline & $n$ & $\%$ \\
\hline \multicolumn{3}{|l|}{ Procedure $(n=113)$} \\
\hline Success & 100 & 89 \\
\hline Failed puncture/dilatation & 6 & \\
\hline Residual cystic duct stone & 6 & \\
\hline Loss of access & 1 & \\
\hline \multicolumn{3}{|l|}{ Stages $(n=100)$} \\
\hline Single & 72 & 72 \\
\hline Multiple & 28 & \\
\hline \multicolumn{3}{|c|}{ Duration of procedure - median $(\min )$} \\
\hline $\begin{array}{l}\text { PCCLs First } 10 \\
\text { PCCLs Last } 50\end{array}$ & $\begin{array}{r}166 \\
51\end{array}$ & \\
\hline \multicolumn{3}{|c|}{ Hospital stay (from initial stage) - median (days) } \\
\hline Elective single & 2 & \\
\hline Elective staged & 5 & \\
\hline Acute & 12 & \\
\hline \multicolumn{3}{|l|}{ Convalescence - median (days) } \\
\hline Full recovery & 12 & \\
\hline Employment & 18 & \\
\hline
\end{tabular}


TABLE VI Outcome. Symptoms, stone recurrence and gall bladder function (emptying) were assessed at a median of 14 months after treatment

\begin{tabular}{llcr}
\hline Outcome & & $n=92$ & $\%$ \\
\hline Symptoms & Score & & \\
None & 0 & 73 & 79 \\
Minimal discomfort & 1 & 10 & 11 \\
Improved & 2 & 3 & 3 \\
No change & 3 & 6 & 7 \\
Ultrasound assessment & & 83 & 90 \\
Stone free & 9 & 10 \\
Definite stones & 5 & \\
Residual & 4 & \\
De novo & 86 & 93 \\
Functioning & $8 / 10$ & \\
Post acute complication & $11 / 13$ & \\
Pre PCCL Hartmann pouch stone & 6 & 7 \\
Non-functioning & 2 & \\
Contracted post-empyema & 4 & \\
Patent cystic duct & & & \\
\hline
\end{tabular}

PCCL = percutaneous cholecystolithotomy

unrelated to the procedure and six have been lost to follow up having left the country. Ninety two patients have been followed for a median 14 months (range six to 37 months).

\section{Clinical follow up}

Scores comparing symptoms before treatment and at follow up are shown in Table VI. The majority of patients $(90 \%)$ have been completely cured of their symptoms (score 0 ) or have had their major symptoms cured and occasionally experience minor discomfort (score 1). Symptoms were unchanged in $7 \%$ of patients and therefore were unlikely to have been caused by gall stones.

\section{Radiological follow up}

Nine of 92 patients $(9 \cdot 8 \%)$ have reformed stones (Table VI). The number of patients with recurrent stones compared with the total number scanned was three of 72 at three to five months, two of 82 at six to 11 months, two of 56 at 12-17 months, one of 21 at 18-23 months, one of three at 24-35 months, and 0 of two at 36-47 months. Stone recurrences in five patients are believed to be the result of residual stones as they reformed by the six month follow up examination and each of the post procedure contrast studies had shown a filling defect in the neck of the gall bladder or cystic duct. They were classified as successes of treatment as subsequent radiological examination had been normal. Seven of the nine patients with stone recurrence are asymptomatic (symptom score 0 ) and the other two have a symptom score of 1 . When gall bladder emptying was assessed $86(93 \%)$ showed a reduction in volume of $>30 \%$ after the fatty meal stimulus. Gall bladder emptying was restored to eight of 10 patients managed with an acutely inflamed gall bladder and to 11 of 13 patients with nonfunction because of a stone impacted in Hartmann's pouch (Table II). Of the six patients with poor or absent gall bladder emptying (nonfunction) two had patent cystic ducts after treatment of perforated empyemas but have since developed contracted, thick walled gall bladders. Both are asymptomatic. The other four patients had non-functioning gall bladders before and after treatment but their cystic ducts were patent at percutaneous cholecystolitho- tomy, and it is assumed that they do not respond to the fatty meal stimulus used to test gall bladder emptying.

\section{Effect of adjuvant bile acid therapy}

Adjuvant bile acid therapy was administered to the last 56 patients who underwent successful percutaneous cholecystolithotomies. Only one of nine patients with stone recurrence received adjuvant bile acid therapy and treatment was stopped after two weeks in this patient because of side effects from the therapy. This patient's stone recurrence was noted within three months of the procedure.

\section{Residual cystic duct stones}

Of seven patients whose percutaneous cholecystolithotomy failed because of residual cystic duct stones, only two were advised to undergo cholecystectomy and the remainder have been followed up for a median of 14 months. Four are asymptomatic (symptom score 0 ) and one has minimal discomfort (sympton score 1). There has been no gall bladder stone recurrence and function has returned to two of the five, possibly because of spontaneous passage of the cystic duct stone.

\section{Discussion}

Although, cholecystectomy is the most effective long term treatment for gall bladder stones, ${ }^{12}$ not all patients are suitable even for the modern techniques of undertaking cholecystectomy, through mini-incisions or laparoscopically, and will continue to require non-operative management of their gall stones. One of the main advantages of percutaneous cholecystolithotomy over other non-operative techniques is that it can be used for $78 \%$ of patients, with stones of any composition, number and size, and a patent cystic duct is not essential. The treatment is successful in $89 \%$ of patients and is complete with full recovery of the majority of patients within two to three weeks. How does this technique compare with other non-operative treatments for gall bladder stones? Probably as few as $10 \%$ of patients are suitable for bile acid therapy, $10-25 \%$ for extracorporeal shockwave lithotripsy combined with adjuvant bile acid therapy and $20 \%$ for contact dissolution with methyl tert-butyl ether. ${ }^{1+}$ Dissolution therapy with bile acids is moderately effective and dissolves cholesterol stones in $40-60 \%$ of carefully selected patients. ${ }^{13}$ Although, extracorporeal shockwave lithotripsy with adjuvant bile acid therapy has been reported to produce stone clearance in $91 \%$ of patients at 12-18 months after stone fragmentation, $83 \%$ of these patients had solitary stones. ${ }^{1+}$ The value of this treatment for multiple stones, which would include $76 \%$ of our patients, is less certain. These completely non-invasive techniques have the advantage of being carried out on an outpatient basis but the treatment may take up to two years. Ultrasound guided minicholecystostomy with radiological stone removal ${ }^{15}$ and laparoscopic cholecystolithotomy ${ }^{16}$ are more invasive than percutaneous 
cholecystolithotomy but can be used if expertise to percutaneously puncture the gall bladder is not available.

In this study, 107 patients (95\%) underwent successful clearance of gall bladder stones but seven of these had a residual cystic duct stone, reducing the overall success rate to $89 \%$. Only two of the patients with residual cystic duct stones were advised to undergo cholecystectomy and the remainder are asymptomatic. In their separate experience, Kellett et al reported successful stone clearance in 56 of 60 fit patients $(93 \%)$ with non-acute gall stone disease. ${ }^{17}$ None of their patients had cystic duct stones. Unlike other non-operative treatments, a nonfunctioning gall bladder with a stone impacted in Hartmann's pouch is not a contraindication to treatment and stones were removed successfully in 15 of 16 patients with a return of cystic duct patency. Draining the gall bladder for seven to 10 days before stone extraction allowed the stone to disimpact in over half of the patients making stone extraction easier. Patients with acute complications of gall bladder stones, were similarly managed by drainage to allow the acute inflammation to resolve before stone extraction was attempted. The safety and efficacy of undertaking stone extraction in the acute gall bladder, when it is friable and difficult to examine thoroughly, is questionable. There has been no mortality associated with percutaneous cholecystolithotomy and most of the complications occurred during development and refinement of the technique. The transperitoneal approach to the gall bladder is usually avoided because of the risk of intraperitoneal bile leakage or bowel perforation. The approach enables larger cannulae to be used for easier stone extraction, however, and avoids unnecessary trauma to the liver. Hruby et al assessed 100 computed tomography scans of gall bladders in gall stone patients and predicted that safe peritoneal puncture was not possible in $34 \%$ of patients. ${ }^{18}$ Our experience with the transperitoneal approach does not confirm these findings. Intraperitoneal bile leakage only occurred early in the study when it was our policy to spigot the drainage catheter after 48 hours, rather than maintain free drainage until a tract to the skin had formed. There has been no injury to bowel in the 113 patients in whom the procedure was attempted, although others have reported this complication. ${ }^{17}$

After cholecystectomy, $30-50 \%$ of patients develop post cholecystectomy symptoms and $34-50 \%$ of these complain of wound pain one to two years later. ${ }^{19}{ }^{20}$ Although the gall bladder is considered to be dispensible, its preservation may result in a reduction of post cholecystectomy symptoms. In this study, $79 \%$ of patients were cured of their symptoms. Seven per cent reported that their symptoms were unchanged which reflects the difficulty of being certain that symptoms are caused by gall stones. With the minimal scarring of a $1 \mathrm{~cm}$ incision, wound pain has not been a problem. Overall, there seems to be a lower incidence of symptoms after percutaneous cholecystolithotomy than cholecystectomy. The main argument against any method which preserves the gall bladder is stone recur- rence but to assume that all patients will develop stone recurrence is incorrect. Stone recurrence after bile acid therapy occurs in approximately $50 \%$ of patients within five years of treatment and then reaches a plateau of $61 \%$ by the 11 th year. ${ }^{21}{ }^{22}$ The early recurrences may be the result of incomplete clearance of the gall bladder which is not detected by radiological examination. Stone recurrence after extracorporeal shockwave lithotripsy is expected to be similar and has been reported as $9 \%$ in the first year. ${ }^{23}$ It is too early to establish whether recurrent stone formation after percutaneous cholecystolithotomy differs from other non-operative treatments. Recurrent stones in five of the nine patients followed up for a median of 14 months are believed to have developed from residual fragments. Even with endoscopic clearance, which should be more thorough, it is often difficult to remove radiologically undetectable, tiny fragments adherent to or embedded in the mucosa and therefore, latterly, patients have been given adjuvant bile acid therapy for an arbitrary three month period. The only patient given bile acid therapy who developed stone recurrence, stopped treatment after only two weeks because of side effects. Stone recurrence in these patients seems to be less than those not given adjuvant therapy but the length of follow up is shorter. In the future, it may be feasible to ablate the gall bladder by thermal or chemical injury or to prevent gall stone formation by altering bile metabolism. ${ }^{2 .}$ After percutaneous cholecystolithotomy, the majority (93\%) of gall bladders emptied satisfactorily including patients who had nonfunctioning gall bladders before treatment because of an acute complication or an impacted stone. This finding adds support to the argument for the continued use of methods which preserve the gall bladder.

Percutaneous cholecystolithotomy is a highly successful, minimally invasive technique with a short hospital stay and rapid convalescence. It has proved particularly useful for the management of high risk patients such as the medically unfit, frail and elderly in whom cholecystectomy is associated with mortality rates of $10 \%$, or higher when carried out for acute complications. ${ }^{25}$ Its use in other groups of patients is likely to remain controversial, particularly with the introduction of less invasive methods of cholecystectomy, such as minicholecystectomy and laparoscopic cholecystectomy.

1 Cheslyn-Curtis S, Russell RCG. New trends in gallstone management. Brf Surg 1991; 78: 143-9.

2 vanSonnenberg E, D'Agostino HB, Casola G, Varney RR Ainge GD. Interventional radiology in the gallbladder: diagnosis, drainage, dissolution, and management of stones. Radiology 1990; 174: 1-6.

3 McGahan JP, Lindfors KK. Percutaneous cholecystostomy: an alternative to surgical cholecystostomy for acute an alternative to surgical cholecystost
cholecystitis. Radiology 1989; 173: 481-5.

4 Leuschner U, Hellstern A, Schmidt K, Fischer H, Guldutun $\mathrm{S}$, Hubner $\mathrm{K}$, et al. Gallstone dissolution with methyl tertbutyl ether in 120 patients - efficacy and safety. Dig Dis Sc 1991; 36: 193-9.

5 Akiyama H, Nagusa Y, Fujita T, Shirane N, Sasao T, Iwamor $\mathrm{S}$, et al. A new method for nonsurgical cholecystolithotomy. Surg Gynecol Obstet 1985; 161: 73-4.

6 Kerlan RK, LaBerge JM, Ring EJ. Percutaneous cholecystolithotomy: preliminary experience. Radiology 1985; 157 653-6.

7 Kellett MJ, Wickham JEA, Russell RCG. Percutaneous cholecystolithotomy. $B M F$ 1988; 296: 453-5.

8 Dowling RH. Medical treatment of gallbladder stones: good news and bad news. In: Paumgartner G, Stiehl A, Gerok W, eds. Trends in bile acid research. Dordrecht: Kluwer Academic, 1988: 283-305. 
9 Schneider AJL. Assessment of risk factors and surgical outcome. Surg Clin N Am 1983; 63: 1113-26.

10 Dodds WJ, Groh WJ, Darweesh RMA, Lawson TL, Kishk SMA, Kern MK. Sonographic measurement of gallbladder volume. Am F Radiol (Roentenol) 1985; 145: 1009-10.

11 Wickham JEA, Miller RA. Percutaneous renal surgery. London: Churchill Livingstone, 1983.

12 McSherry CK. Cholecystectomy: the gold standard. Am f Surg 1989; 158: 174-8.

13 Maton PN, Iser JH, Reuben A, Saxton HM, Murphy GM Dowling RH. Outcome of chenodeoxycholic acid (CDCA) treatment in 125 patients with radiolucent gallstones. Medicine 1982; 61: 85-96.

14 Sackmann M, Delius M, Sauerbruch T, Holl J, Weber W, Ippisch E, et al. Shock-wave lithotripsy of gallbladder stones. The first 175 patients. $N$ Engl F Med 1988; 318: 393-7.

15 Gibney RG, Fache JS, Becker CD, Nichols DM, Cooperberg PL, Stoller JL, et al. Combined surgical and radiological patients. Radiology 1987; 165: 715-9.

16 Perissat J, Collet DR, Belliard R. Gallstones: laparoscopic treatment, intracorporeal lithotripsy followed by cholecystostomy or cholecystectomy - a personal technique. Endoscopy $1989 ; 21: 373-4$.

17 Chiverton SG, Inglis JA, Hudd C, Kellett MJ, Russell RCG, Wickham JEA. Percutaneous cholecystolithotomy: the first 60 patients. BMF 1990; 300: 1310-2.
18 Hruby W, Urban M, Stackl W, Armbruster C, Marberger M. Stonebearing gallbladders: CT anatomy as the key to safe Stonebearing gallbladders: CT anatomy as the key
percutaneous lithotripsy. Radiology 1989; 173: 385-7.

19 Bates T, Ebbs SR, Harrison M, A'Hern RP. Influence of cholecystectomy on symptoms. Br $\mathcal{F}$ Surg 1991; 78:

20 Ros E, Zambon D. Postcholecystectomy symptoms. A prospective study of gall stone patients before and two years after surgery. Gut 1987; 28 : 1500-4.

21 Dowling RH, Gleeson DC, Hood KA, Ruppin DC, BritishBelgian Gallstone Study Group. Gallstone recurrence and postdissolution management. In: Paumgartner G, Stiehl A, Gerok W, eds. Bile acids and the liver. Lancaster, England: MTP Press, 1987: 355-67.

22 Villanova N, Bazzoli F, Taroni F, Frabboni R, Mazzella G, Festi $\mathrm{D}$, et al. Gallstone recurrence after successful oral bile acid treatment. A 12-year follow-up study and evaluation of long-term postdissolution treatment. Gastroenterology 1989; 97: $726-31$.

23 Sackmann M, Ippisch E, Sauerbruch T, Holl J, Brendel W, Paumgartner. Early gallstone recurrence rate after successful shock-wave therapy. Gastroenterology 1990; 98: 392-6.

24 Becker CD, Quenville NF, Burhenne HJ. Gallbladder ablation through radiologic intervention: an experimental alternative to cholecystectomy. Radiology 1989; 171: 235-40.

25 Huber DF, Martin EW, Cooperman M. Cholecystectomy in elderly patients. Am F Surg 1983; 146: 719-21. 